\title{
Quantitative Coastal Resilience Assessment Framework under Climate Change and Sea Level Rise
}

Tao $\mathbf{W u}^{*}$

* Department of Plant Science and Landscape Architecture, University of Connecticut, Storrs 06268, USA; tao.2.wu@uconn.edu; Tel.: +1 8606346907

\begin{abstract}
Accompanied by increasing population growth and urban sprawl, most coastal cities are unprecedentedly vulnerable to climate change and its impacts, such as sea level rise, increasing extreme storm events, and coastal flooding. Coastal resilience and sustainable development are antidotes to vulnerability; they aim to enhance the adaptive capability of absorbing disturbances and resisting uncertainty. This study explores building a quantitative assessment framework to measure resilience and provide an objective and comparable method to understand the strengths and weaknesses in a given region. The proposed 25 resilience indicators incorporate the aspects of essential livelihood protection, infrastructure and natural resource maintenance, emergency facilities and institutions, floodplain management regulations, and adaptive planning process. Each indicator is assigned the resilience quality that includes robustness, resourcefulness, redundancy, and rapidity. The aggregated resilience quality scoring reflects the systematic performance of the city to cope with the coastal hazards. The innovative part of this framework is combining hazard mitigation measures, climate adaptation strategies, and sustainable development goals together to achieve a comprehensive assessment method. In the case of New Haven, the resilience assessment is taken as a practical monitoring tool and decision-making support.
\end{abstract}

Keywords: coastal resilience; climate change; indicators; social-ecological system

\section{Introduction}

Coastal regions and populations are exposed to pressures and hazards from both land and ocean, making the coastal zone the most transformed and imperiled social-ecological system on the earth [1]. According to Intergovernmental Panel on Climate Change (IPCC) report, global warming and climate change dramatically alter coastal land and affect people's living conditions. Global warming causing glacial melting and thermal expansion of water results in sea level rise and triggers swath of land loss putting the coastal population at the risk of losing their home. Extreme weather and hurricanes bring catastrophic consequences to coastal areas, and heavy precipitation events are causing inland city flooding that is becoming much more common. Climate change-driven disruptions to ecosystems have direct and indirect human impacts, including reduced water supply and quality, the loss of iconic species and landscapes, effects on food chains and the timing and success of species migrations, and the potential for extreme weather to destroy or degrade the ability of ecosystems to provide societal benefits [2].

Urban sprawl has increased the risk of flooding due to the essential elements of hazard exposure, vulnerability, along with the higher population growth leading to higher runoff $[3,4]$. Resilience, in both its social and ecological manifestations, is an important aspect of the sustainability of development and resource utilization. A simple definition of resilience is the ability of a city to absorb disturbance while maintaining its functions and structures $[5,6]$. The notion of resilience is often associated with the ability to learn, primarily in order to become more robust to change [7]. 
Coastal resilience has ecological and socio-economic components, each of which represents another aspect of the coastal system's adaptive capacity to perturbations; integrated assessment and planning tools of these components are meaningful for coastal management [8]. Nature-based solutions (NBS) are increasingly applied to guide the design of resilient landscapes and cities to enable them to reach economic development goals with beneficial outcomes for the environment and society [9]. The resilience of socio-ecological systems to sea level rise, storms, and flooding can be enhanced when coastal habitats are used as natural infrastructure [10].

Currently, the issues of resilience and vulnerability are becoming more critical in resource management and urban development. Resilience is often viewed as an antidote to vulnerability, and resilience planning works to reduce or even eliminate the vulnerability [11]. Some researchers see vulnerability as the opposite of disaster resilience, while others view vulnerability as a risk factor and resilience as the capacity to respond [12]. Achieving resiliency means the ability to survive future natural disaster with minimum loss of life and property, as well as the ability to create a greater sense of place among residents; a stronger, more diverse economy; and a more economically integrated and diverse population $[13,14]$. The issue of climate change is part of the larger challenges of sustainable development and resilience enhancement. As a result, climate policies can be more effective when consistently embedded within broader strategies designed to make national and regional development paths more resilient. The impacts of climate change, climate policy responses, and associated socio-economic development will affect the ability to achieve sustainable development goals [15].

Godschalk [16] argues that the overriding goal for urban hazard mitigation should be to develop resilient cities that would be capable of withstanding severe shock without either immediate chaos or permanent harm. A resilient city is a sustainable network of physical systems and human communities. Physical systems are the constructed and natural environmental components of an area, including roads, buildings, infrastructure, communications, energy facilities, as well as waterways, soils, topography, geology, and other natural systems. The physical systems must be able to survive and function under extreme stresses, otherwise, the city will be extremely vulnerable to disasters. Human communities are the social and institutional components of an area, including neighborhoods, agencies, organizations, enterprises, task forces, and the like. During a disaster, the community networks must be able to survive and function under extreme and unique conditions. Resilient cities composed of networked social communities and the lifeline systems would become more robust by adapting and learning from disasters, rather than brittle or fragile. The assessment of coastal vulnerability and resilience helps identify the strengths and weaknesses, monitor the changes of resilience, allocate mitigation and adaptation resources, and justify the policy to the public [17-19].

The sustainable development goals (SDGs) promoted by United Nations are the world's shared plan to protect the environment, reduce inequality, smart grow, and adapt to changing trends. The 17 goals inclusively and comprehensively cover the social and basic livelihood, economic, environmental, and institutional aspects. The City Resilience Index (CRI) developed by Arup and supported by the Rockefeller Foundation in 2014, provides a holistic articulation of city resilience. It is structured around four dimensions, 12 goals, and 52 indicators that are critical for city resilience building and measuring. SDGs and CRI focus on the same dimensions of cities and generalize the similar main critical aspects toward sustainability and resilience (Table 1). Based on the two systems and related research, this study aims to build a quantitative framework of coastal resilience assessment to help with monitoring resilience and its change, making targeted decisions, and prioritizing mitigation and adaptation actions.

Table 1. Comparison of Sustainable Development Goals of UN and City Resilience Index

\begin{tabular}{ccc}
\hline Dimensions & UN SDGs & CRI \\
\hline Basic Livelihood/ & No poverty & Minimal human vulnerability \\
Health and Well-being & Zero hunger & Diverse livelihoods and employment \\
\hline
\end{tabular}


Good health and well-being

Quality education

Gender equity

Clean water and sanitation

Affordable and clean energy

\section{Reduced inequities}

Economy and Society

Decent work and economic growth

Industry innovation and infrastructure

Responsible consumption and production

\begin{tabular}{ccc}
\hline $\begin{array}{c}\text { Infrastructure and } \\
\text { Environment }\end{array}$ & $\begin{array}{c}\text { Sustainable cities and communities } \\
\text { Climate action } \\
\text { Life below water } \\
\text { Life on land }\end{array}$ & $\begin{array}{c}\text { Reduced exposure and fragility } \\
\text { Effective provision of critical services } \\
\text { Reliable mobility and communications }\end{array}$ \\
\hline Institutions/ & Peace, justice, and strong institutions & Effective leadership and management \\
Leadership and Strategy & Partnerships for goals & Empowered stakeholders \\
\hline
\end{tabular}

Effective safeguards to human health and life

Collective identity and community support

Comprehensive security and rule of law

Sustainable economy

\section{Methods}

In order to characterize subsystems of a region or a city and determine the criteria of resilience assessment, it is necessary to identify the factors and elements that effect on coastal resilience [20-23]. Some researchers have attempted to explore the quantitative and qualitative indicators of socio-ecological system or community resilience assessment [24$28]$ that essentially reduced the complexity of the measuring process.

The framework of coastal resilience assessment proposed by this study adopts four major dimensions of physical, environmental, social and economic, and institutional. Physical resilience focuses on the factors of basic livelihood \& health and well-being, such as safe and affordable housing, adequate clean energy supply, safe water supply and effective sanitation, sufficient food supply and emergency preparedness, and reliable critical facilities and infrastructure. Environmental resilience covers the aspects of well stewardship of ecosystems, effectively managed protective ecosystems, and flexible green infrastructure services and low impact development. Social and economic resilience is related to inclusive labor policy and employment, dynamic and diverse business development, industry innovation and integration with regional economies, supportive public financing mechanism, cohesive communities, and robust public health systems and emergency medical care. Institutional resilience involves the aspects of reliable communication technology, effective emergency response services, appropriate government decision making, proactive stakeholder collaboration and actively engaged citizens, as well as comprehensive data management, appropriate land use and zoning, and consultive planning process.

Under the major dimensions, 25 indicators are framed to cover the aspects that are critical to coastal resilience monitoring and enhancement (Table 2). These indicators were assigned the resilience qualities of robustness, redundancy, resourcefulness, and rapidity. Robustness reflects the ability to withstand a given level of stress or meet the demands; redundancy reflects substitutable and capable of satisfying functional requirements; resourcefulness represents the capacity to identify problems, establish priorities, and mobilize resources; rapidity represents the capacity to meet priorities and achieve goals in a timely manner. The data sources are from governmental and organizational documents or regulations, local planning documents, and public open data to ensure the results could be validated, monitored, and improved with new data updated by stakeholders.

Table 2. The framework of quantitative coastal resilience assessment and the indicators in measuring resilience

\begin{tabular}{cllcc}
\hline System & No. & \multicolumn{1}{c}{ Resilience elements } & Qualities & Data Source $^{1}$ \\
\hline \multirow{3}{*}{ Physical resilience } & 1 & Buildings up to flood building codes (\%) & Robustness & FEMA \\
& 2 & Water supply up to floodplain management regulations (\%) & Robustness & HMP \\
& 3 & Sewage system up to floodplain management regulations (\%) & Robustness & HMP DEEP
\end{tabular}


4 Energy supply to meet normal and emergency need (\%)

$\begin{array}{cc}\text { Robustness } & \text { HMP } \\ \text { Robustness } & \text { HMP } \\ \text { Robustness } & \text { HMP } \\ \text { Rapidity } & \text { HMP } \\ \text { Resourceful } & \text { HMP } \\ \text { Resourceful } & \text { HMP }\end{array}$

5 Drainage capacity and pump station coverage (\%)

6 Engineered hazard mitigation measures (\%)

7 Accessibility of evacuation routes (\%)

8 Number and capacity of shelters (per mi²)

Robustness HMP

10 Living shoreline (\%)

Redundancy

DEEP

Environmental

11 Green infrastructure and LID (\%)

Redundancy

DEEP resources (\%)

13 Housing with flood insurance (\%)

14 Institutions or organizations for flood emergency (American Red Cross, first responder, etc.)

Social and economic

15 Social vulnerability and equity resilience

16 Sustainable and innovative industries (\%)

$\begin{array}{cc}\text { Resourceful } & \text { HMP } \\ \text { Rapidity } & \text { GD }\end{array}$

Robustness CDC

17 Diversified industries

Resourceful

$\mathrm{CP}$

Redundancy

$\mathrm{CP}$

18 Climate adaptation investment

Robustness

HMP

19 Market-based incentives to encourage appropriate develop-

Resourceful

$\mathrm{CP}$ ment

20 Data management and availability (flood hazard map, sea level rise data, shelter and evacuation map, etc.)

21 Comprehensive assessments and monitoring

Resourceful

GD

Comprehensive assessments and monitoring

Redundancy

HMP

Institutional cast, early flood warning systems, etc.)

resilience

23 Public awareness and education for coastal hazard

24 Stakeholder engagement and interdisciplinary collaboration

25 Regulation and policy (floodplain management guidance, building codes, land acquisition and buyout policy, etc.)

Rapidity

GD

Robustness HMP

Resourceful HMP

Robustness HMP

${ }^{1}$ FEMA = Federal Emergency Management Agency, HMP = Hazard Mitigation Plan, DEEP = Department of Energy and Environmental Protection, $\mathrm{GD}=$ Governmental Documents, $\mathrm{CDC}=$ Centers for Disease Control and Protection, $\mathrm{CP}=$ Comprehensive Plan

This study adopted the scale scoring measurement to enable a meaningful comparison $[29,30]$. Each indicator is rated on a scale of one to five according to their performance or capacity, with a score of one reflecting poor performance or limited capacity, five indicating well performance or adequate capacity. Scores between one and five reflecting a gradient increase. The city of New Haven, Connecticut, USA, is taken as an example to assess coastal resilience (Table 3 ).

New Haven is one of the most flood-vulnerable cities in the state, with high developed land use ratio, high socio-economic vulnerability, and severe hazard exposure, especially in the coastal districts and highly populated downtown areas. New Haven also features the highest impervious land cover ratio and highest coastal artificially filled land ratio in the state. The city has fewer green spaces to offset the natural hazard impacts but has high population density and social vulnerability index, which intensified the coastal vulnerability. Low elevation, high risk of hurricane surge inundation, and frequent coastal flooding even worsen the situation. In order to cope with these problems and adapt to the changing climate, the city formulated the hazard mitigation plan and sustainable development plan, as well as implemented various mitigation and adaptation projects. This study compared the score of 2017 and planned scenarios of 2025 to examine the systemic strengths and weaknesses, and prioritize the actions and tasks that enhance coastal resilience.

\section{Results}


Each of the 25 indicators of resilience was assigned a value between one to five according their performance or capacity by processing public datasets and examining the relevant report. The coastal resilience scores of New Haven in 2017 sum up to 97, compared with 110 of the planned scenario in 2025 according to the development vision and climate adaptation plan (Table 3).

Table 3. Scoring criteria of resilience assessment and rating New Haven coastal resilience

\begin{tabular}{|c|c|c|c|c|c|c|c|c|}
\hline \multirow{2}{*}{\multicolumn{2}{|c|}{ Resilience indicators }} & \multicolumn{5}{|c|}{ Scoring criteria } & \multicolumn{2}{|c|}{ Score } \\
\hline & & 1 & 2 & 3 & 4 & 5 & 2017 & Planned \\
\hline 1 & Buildings up to flood codes & $0-20 \%$ & $20-40 \%$ & $40-60 \%$ & $60-80 \%$ & $80-100 \%$ & 4 & 4 \\
\hline 2 & Water supply & poor & - & - & - & well & 5 & 5 \\
\hline 3 & Sewage system & poor & - & - & - & well & 4 & 5 \\
\hline 4 & Energy supply & poor & - & - & - & well & 4 & 4 \\
\hline 5 & Drainage system & inadequate & - & - & - & adequate & 3 & 4 \\
\hline 6 & Hazard mitigation measures & inadequate & - & - & - & adequate & 3 & 4 \\
\hline 7 & Accessibility of evacuation routes & limited & - & - & - & good & 4 & 4 \\
\hline 8 & Capacity of shelters & low & - & - & - & high & 5 & 5 \\
\hline 9 & Critical facilities & $\begin{array}{l}\text { inadequate } \\
\text { and unsafe }\end{array}$ & - & - & - & $\begin{array}{l}\text { adequate } \\
\text { and safe }\end{array}$ & 4 & 5 \\
\hline 10 & Living shoreline & $0-20 \%$ & $20-40 \%$ & $40-60 \%$ & $60-80 \%$ & $80-100 \%$ & 2 & 3 \\
\hline 11 & Green infrastructure and LID & none & - & - & - & plenty & 3 & 4 \\
\hline 12 & Ecosystem and natural resources & none & - & - & - & plenty & 4 & 4 \\
\hline 13 & Housing flood insurance & $0-20 \%$ & $20-40 \%$ & $40-60 \%$ & $60-80 \%$ & $80-100 \%$ & 4 & 5 \\
\hline 14 & Institutions for flood emergency & $\begin{array}{l}\text { poor-orga- } \\
\text { nized }\end{array}$ & - & - & - & $\begin{array}{l}\text { well-orga- } \\
\text { nized }\end{array}$ & 4 & 5 \\
\hline 15 & Social vulnerability Index & $1-0.8$ & $0.8-0.6$ & $0.6-0.4$ & $0.4-0.2$ & $0.2-0$ & 2 & 3 \\
\hline 16 & $\begin{array}{l}\text { Sustainable and innovative indus- } \\
\text { tries }\end{array}$ & $\begin{array}{l}\text { unsustainable, } \\
\text { traditional }\end{array}$ & - & - & - & $\begin{array}{l}\text { sustainable, } \\
\text { innovative }\end{array}$ & 3 & 4 \\
\hline 17 & Diversified industries & similar & - & - & - & diversified & 4 & 5 \\
\hline 18 & Climate adaptation investment & low & - & - & - & high & 3 & 4 \\
\hline 19 & $\begin{array}{l}\text { Incentives to encourage appropri- } \\
\text { ate development }\end{array}$ & low & - & - & - & high & 4 & 4 \\
\hline 20 & Data management and availability & incomplete & - & - & - & complete & 5 & 5 \\
\hline 21 & $\begin{array}{l}\text { Comprehensive assessments and } \\
\text { monitoring }\end{array}$ & poor & - & - & - & well & 4 & 4 \\
\hline 22 & Communication system & poor & - & - & - & well & 5 & 5 \\
\hline 23 & Public awareness and education & limited & - & - & - & broad & 4 & 5 \\
\hline 24 & $\begin{array}{l}\text { Stakeholder engagement and in- } \\
\text { terdisciplinary collaboration }\end{array}$ & limited & - & - & - & broad & 4 & 5 \\
\hline 25 & Regulation and policy & inadequate & - & - & - & adequate & 4 & 4 \\
\hline & Total & & & & & & 97 & 110 \\
\hline
\end{tabular}

\subsection{Physical and environmental resilience scoring}

\subsubsection{Buildings in the 100 -year flood area}

In order to regulate the construction in the flood area, floodplain management regulations and building codes are generally adopted and enforced. The Connecticut Building Code adopted in 2016 requires all construction of buildings and structures meeting or exceeding the minimum National Flood Insurance Program (NFIP) for flood risk reduction and flood damage prevention. In New Haven, about $12 \%$ of buildings are located in the 100-year flood area, which is designated by Federal Emergency Management Agency (FEMA), and most were built before flood building codes and not up to flood building codes. With sea level rising, FEMA continues to expand the flood risk zone and raise base 
flood elevation, which makes more buildings below the requirements. Under new planned development and retrofitting projects and relocation of the vulnerable building, the climate change impacts on coastal structures can be offset by these strategies.

\subsubsection{Water supply, sewage system, and energy supply}

The basic livelihood of water supply, sanitation, and energy supply is critical for normal daily life and reflects the urban system's robustness to risk. The Regional Water Authority serves 123,100 (94\% of New Haven's population) in its service area. An Emergency Operations Center allows for a full operational response. The authority continues to implement and maintain improvements and periodically tests its alternative emergency operations center according to the updated HMP (2016).

The centralized wastewater system covers $63 \%$ area of New Haven and most of the urbanized area. Sewage is pumped to the water pollution abatement facility and treated and discharged into New Haven Harbor. However, New Haven has a combined sewer collection system in certain sections of the city, and the wastewater facility treats approximately $89 \%$ of the combined sewer flow, while about $11 \%$ overflows at the CSO (Combined Sewer Overflows) outfalls into local rivers and the harbor. The long-term wastewater control plan aims to eliminate $100 \%$ of CSOs and improve the water quality of the riverine and coastal area.

New Haven's energy supply provides natural gas and electricity. The gas company has an emergency plan in place that is routinely updated; they also have their staff stationed in the Office of Emergency Management along with other city officials to discuss emergency plans in case of an impending disaster. The electricity company launched a vegetation program and management specifications to increase the distance between vegetation and power lines after witnessing the damage caused by tropical storm Irene (2011) and Superstorm Sandy (2012). But there is no backup energy supply during an emergency according to updated HMP and exists hidden trouble.

\subsubsection{Drainage system and coastal hazard mitigation measures}

The drainage system is a crucial part of flood mitigating measures, while the performance of a drainage system varies by facility type and environmental setting [31]. In multiple areas, problems that cause coastal flooding in the low-lying area are primarily due to artificially filled land in New London. The high impervious cover in the downtown area leads to flash flooding and significantly contributes to coastal area flooding. The drainage system's capacity needs more improvement to deal with the intensified flood problems caused by more frequent extreme weather events and rising sea levels. Although 17 pump stations are scattering the city, fewer are located in the coastal regions. The city implemented a green stormwater drainage strategy and installed green infrastructure to alleviate flood problems and plans to construct more in the 2025 vision.

In the nearly 9-mile shoreline, the artificially modified shoreline accounts for more than 40 percent. The hazard mitigation measures for these areas include bulkhead, revetment or rip-rap, and seawalls, while most of them are vulnerable to intense coastal storms and erosion. The hazard mitigation plan and resilience plan incorporated shoreline ecosystem restoration and living shoreline enhancement projects. However, with rising sea levels, more adaptation measures to help wetlands migration and managed retreat strategy to protect natural resources are needed.

\subsubsection{Emergency preparedness and responses}

Emergency preparedness plays a vital role in preventing, preparing for, and responding to the adverse effects of natural hazards and disasters. New Have has an evacuation route plan, but parts of the routes are located in low-lying areas and vulnerable to flooding. According to the survey, in the event of an emergency, only $26 \%$ population is aware of the evacuation routes, which may compromise the effectiveness of the evacuation.

New Haven has six shelters that are capable of sheltering approximately 3,145 individuals based on numbers of cots in American Red Cross certified facilities and accommodates the evacuation of nearly 16,795 individuals according to the New Haven 
Emergency Operation Plan (2013). The population exposed to flood vulnerability is about 13,250 that is covered by the shelter planning.

The city's police, fire, medical, governmental, and major transportation facilities are critical assets that ensure public safety and efficiency of community operations in both day-to-day activities and emergencies. The emergency operations center serves as the headquarters for emergency management. The spatial distribution of these facilities is applicable, but some are located in the floodplain and exposed to coastal hazards.

\subsubsection{Green infrastructure and living shoreline}

The green infrastructure consists of green spaces, waterbody, and built systems, e.g., forests, wetlands, parks, green roofs, rain gardens, and bioswales that together can contribute to ecosystem resilience and human benefits through ecosystem services [32]. New Haven is a highly urbanized city with $73 \%$ developed land cover and $100 \%$ of the population living in the urbanized area. The natural system only accounts for $27 \%$ of land cover and is unevenly distributed along the river and shoreline that provides critical ecosystem services, including hazard mitigation. The limited green spaces are well stewarded by the city, green infrastructure were installed to alleviate pressure on the storm sewer system, but the natural systems are extremely vulnerable due to fragmentation and disconnection.

Living shoreline is a broad term that encompasses a range of shoreline stabilization techniques along coastlines (NOAA). A living shoreline has a footprint that is made up mostly of native material including vegetation or other living, natural "soft" elements alone or in combination with some type of harder shoreline structure (e.g., oyster reefs or rock sills) for added stability. Currently, part of shorelines in New Haven were facilitated living shoreline solutions, and their length is no more than $40 \%$ of total shorelines. Future restoration and enhancement aims to increase this percentage. However, with the rising sea level, many engineered shoreline protection measures will be ineffective, and more living shorelines will be needed.

\subsection{Social and economic resilience scoring}

\subsubsection{Housing flood insurance}

Flood insurance protects the homes from devastating loss in extreme weather events and is a critical part of social and economic resilience. According to the updated HMP, as of 2016, there were 947 flood insurance policies within the city, representing roughly $74 \%$ of buildings in the floodplain. The city entered FEMA's Community Rating System (CRS) program and was eligible to become a class 7 community in 2017, which resulted in a $15 \%$ flood insurance discount for properties in the flood area of the city. The improved CRS class provides a lower flood insurance rate and attracts more homes to enroll in the National Flood Insurance Program.

\subsubsection{Social and economic vulnerability}

Social vulnerability refers to the potential adverse effects on communities caused by external stresses on human and social health. Reducing social vulnerability can decrease both human suffering and economic loss. CDC's Social Vulnerability Index (CDC SVI) uses 15 US census variables to help local officials identify communities that may need support before, during, or after disasters. The value of SVI ranges from 0 to 1 and represents the percentile ranking in the state.

The average SVI rating of New Haven is 0.73 that indicates a high social vulnerability level in the state. Among the 31 census tracts, 11 tracts' SVI is higher than 0.9 , and 8 tracts' SVI is between 0.8 and 0.9 , suggesting more than $60 \%$ of areas are in very high socialeconomic vulnerability. In addition, 8 tracts' SVI is lower than 0.5 , comparing with the most vulnerable tracts in New Haven, which reveals a polarization of social-economic vulnerability and potential inequity (Figure 1). Regarding spatial distribution, the tracts with high social-economic vulnerability are mainly concentrated in coastal and riverine areas with high flood hazard risk. The New Haven updated HMP and Comprehensive Plan of Vision 2025, set the goals to promote sustainable and balanced economic growth 
and initiate a series of coastal and riverine industrial transformation planning, the socialeconomic vulnerability may be reduced under these strategies.
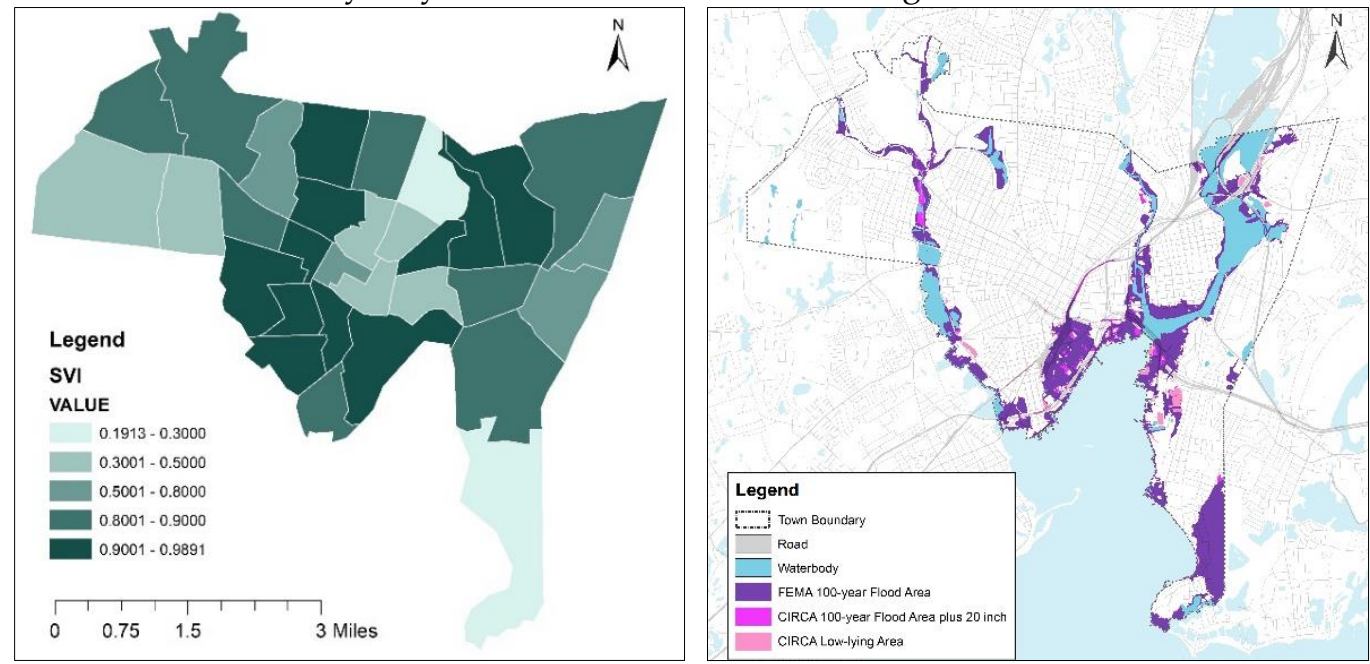

Figure 1. Comparison of New Haven social vulnerability and flood hazard zones: (a) social vulnerability index (SVI) map, (b) overlay map of FEMA 100-year flood hazard and projected 100-year flood hazard.

\subsubsection{Diversified, sustainable, and innovative industries}

In order to increase the ability to attract business investment, allocate capital, and build emergency funds, the city needs a robust, flexible, and diverse local economy. New Haven's economy was based on the manufacturing industry; after the 1950s, the base of the economy has shifted to health, business, financial services, and biotech. Some coastal industrial areas face the challenge of high unemployment and in need of transformation. The city's master plan proposed an all-inclusive economy by encouraging neighborhoodbased economic development initiatives, which consider a neighborhood's assets and opportunities by supporting the equitable distribution of resources in Vision 2025. The city plans to promote specialty manufacturers and numerous high-quality food producers and distributors; facilitate more innovative entrepreneurs to move in. The original waterfront district is planned to introduce innovative industries, new markets, and parkways.

\subsubsection{Climate adaptation investment and market-based incentives}

Climate investment and incentives are essential strategies to empower transformations in clean energy technology, climate resilience, and sustainable development. New Haven continues to invest in coastal and inland flood structures, e.g., floodgate, revetment, living shoreline, rain gardens, and bioswales. However, the large area of vulnerable harbor district needs continuous investment to adapt to intensified coastal storms and rising sea levels and facilitate the land acquisition.

Market-based incentives to encourage appropriate development in New Haven include the Waterfront Plan that focuses on market-driven and phased redevelopment, Transit-Oriented Development (TOD) that emphasizes the public realm and generating jobs, improving the city's connectivity, increasing walkability. Still, there are some vacant lots and under-utilized lands in the coastal industrial area; most of them are in the artifi(cially filled area (Figure 2), and some of therbare also contaminated brownfields. More incentives and funding are needed to encourage appropriate development in the coastal industrial areas and vacant lots to help them to transform. 

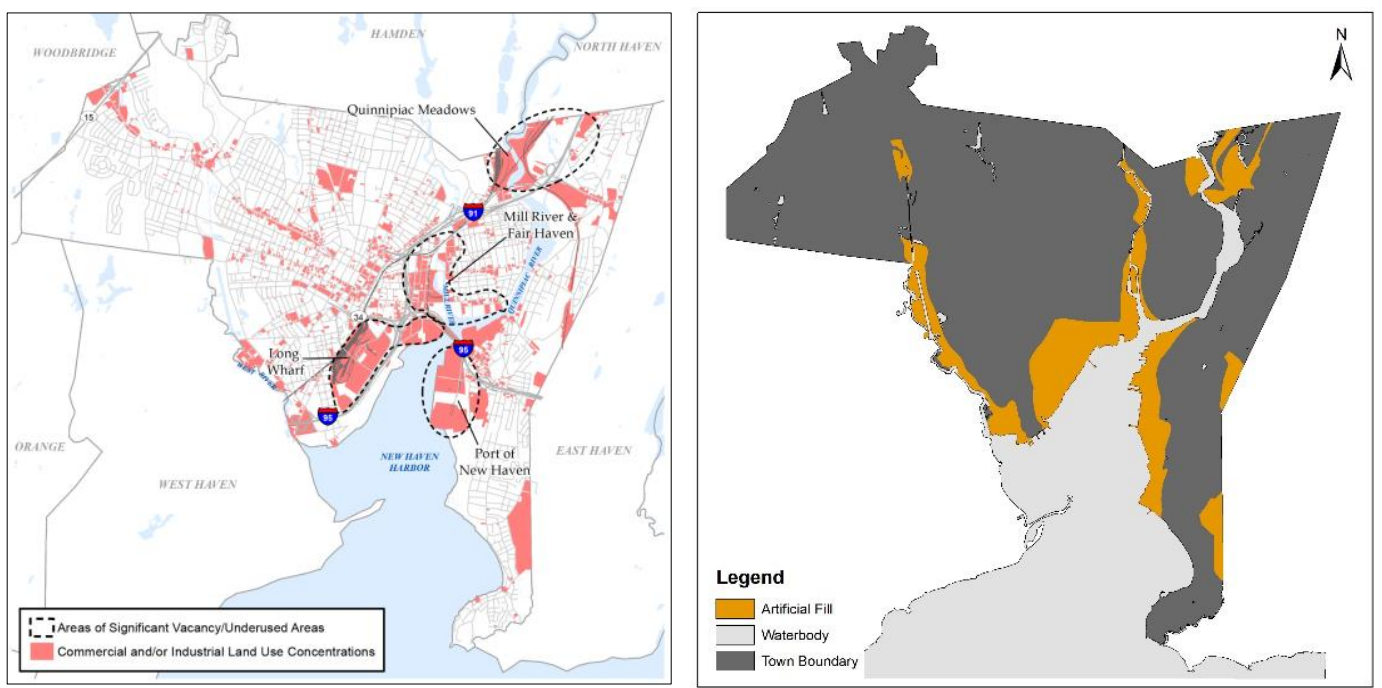

Figure 2. The comparison of vacancy areas and artificially filled land in New Haven: (a) vacancy and underused areas (from New Haven Comprehensive Plan of Vision 2025), (b) artificially fill land along coastline and riverine areas.

\subsection{Institutional resilience scoring}

\subsubsection{Data management and monitoring}

The flood hazard map, sea-level-rise data, shelter and evacuation map, emergency information, conservation and development plan, weather and flood information, etc. are crucial data for coastal hazard preparedness. These data can be accessed from FEMA, HMP, governmental documents, and other open sources of New Haven, and they are updated both timely and periodically.

Most of the resilience elements are monitored by the city or the related department, especially the infrastructure data such as drinking water supply, sewage system, drainage system, roadside trees, etc. However, the city lacks comprehensive assessment and monitoring; and a systemic understanding of vulnerability and resilience is needed for future decision-making and priority identification.

\subsubsection{Public awareness and education}

Communicating the risks effectively with the community and individuals is essential for better preparing the extreme weather event and disasters. In New Haven, the public is actively involved in the hazard mitigation plan and outreach activities, which contribute to public awareness and education for flood hazard risk and climate adaptation, also connect hazard mitigation planning to other community planning efforts. But the survey shows that more than 40 percent of respondents were unaware whether the property they owned is located in a floodplain, and more than 50 percent of respondents reported having little or no knowledge of the national flood insurance program. Thus, Broader public awareness, education, and preparedness are needed in the future.

\subsubsection{Stakeholder engagement and interdisciplinary collaboration}

Stakeholder participation is critical to move from experiential learning to social learning and build resilience to disasters in a changing climate [33,34]. New Haven made a concerted effort to include as many stakeholders and various planning team meetings as they could reach throughout the plan development process. For example, the hazard mitigation activities and planning process involved neighboring communities, local and regional agencies that have the authority to regulate development, and other interests.

\subsubsection{Regulations and policies}

The federal and local governments have the responsibility to manage coastal hazards and help people to recover from a disaster and better cope with future risks [35]. governmental regulation and policy involve construction standards, development specifications, natural resource protection guidelines, and economic support, etc. New Haven adopted FEMA floodplain development regulations, flood building codes, Inland, Wetland and 
Water Courses regulations, floodplain resources protection regulations, and national flood insurance program. But with sea level rise, some coastal lands will not be suitable for habitation and business; the corresponding relocation and land acquisition or buyout policies are needed in future plans.

\subsection{Radar chart analysis}

\subsubsection{Strengths and weaknesses of resilience indicators' performance}

The radar chart of the 25 resilience elements (Figure 3) reveals which factors are well performed or prepared for flood hazards and which are not adequate or in low capacity. For New Haven, social vulnerability, living shoreline, drainage system, and climate adaptation investment are in great need of improvement; in respect to basic livelihood, regulation and policy, stakeholder engagement and interdisciplinary collaboration, the city performs well and has the determination to keep the social-ecological system sustainable and resilient. The discrepancy between vision and reality still needs more actions to fill the gap.

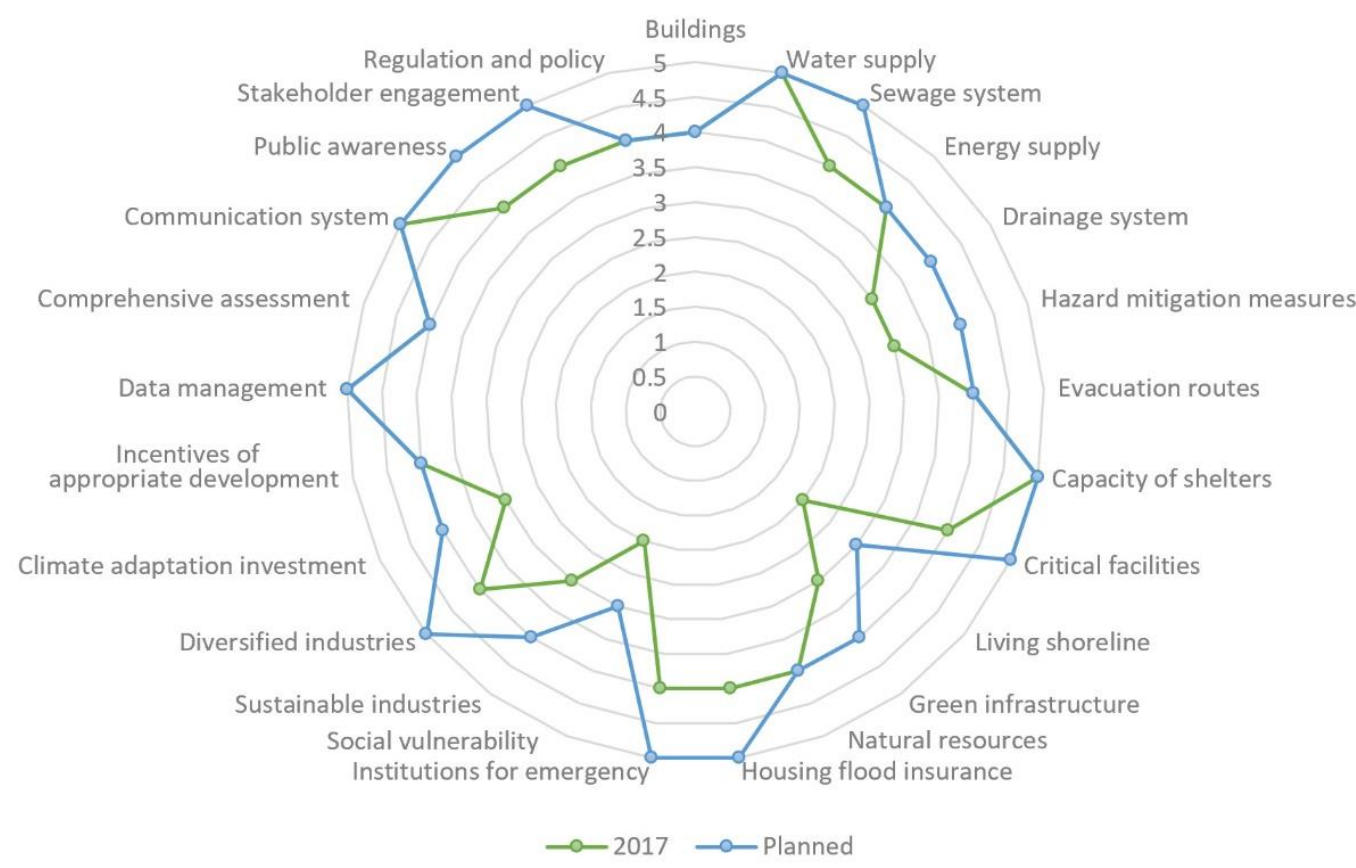

Figure 3. Radar chart of the performance of 25 resilience elements with a comparison between 2017 situation and the planned scenario.

\subsubsection{Monitoring the coastal resilience change}

This quantitative framework of coastal resilience assessment provides a systemic and comparable method to observe a region's capability to respond to coastal hazards and set a benchmark to monitor coastal resilience change. Figure 4 is created to examine the resilience scores of three dimensions and the score comparison between the 2017 and 2025 plan. In respect to physical-environmental resilience, the water supply and sanitation systems, energy supply systems, and shelters have a good performance and capacity. In contrast, the coastal natural system, drainage system, critical facilities, and coastal buildings cannot fully cope with flood hazards or meet safety requirements and need to continuously adapt to the changing situation. The social-economic and institutional resilience also see score increases of planned scenarios compared with the current situation. Thus, the framework may be used to monitor the indicators' performance change and be reassessed periodically, which provides feedback on mitigation or adaptation actions. 
(a)

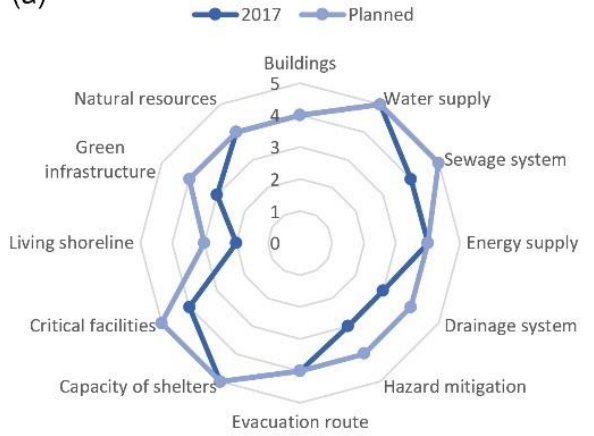

(b)

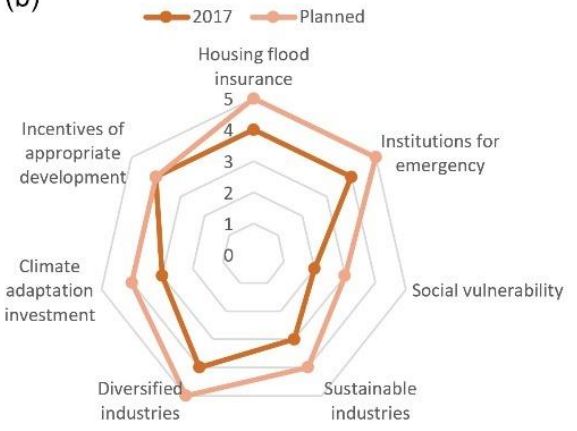

(c)

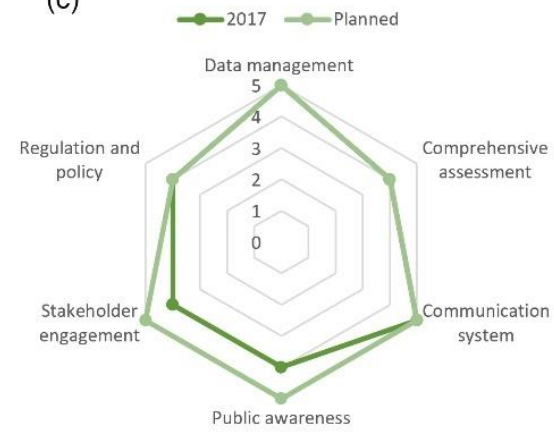

Figure 4. Radar chart of the performance of three dimensions of coastal resilience: (a) physical-environmental resilience score; (b) social-economic resilience score; (c) institutional resilience score.

\subsubsection{Prioritizing coastal resilience enhancement projects}

The purpose of coastal resilience assessment also lies in prioritizing future actions or projects to enhance the capability to cope with natural hazards and adapt to changing climate. The scores support ensuring that the proposed projects are comprehensive in addressing the systematic needs for resilience, rather than only focusing on the easier ones or the most visible to accomplish. For New Haven, more investment may be considered to put in the living shoreline, green infrastructure, and critical facilities construction; the economic incentives should be guided to encourage appropriate development that embodies climate adaptation and sustainable development goals in coastal vacant areas; public participatory and education should be promoted to raise broader awareness of climate change and its impacts, and to explore creative adaptation actions.

\subsection{Aggregated resilience quality scoring}

The 25 resilience indicators were assessed with a quality description shown in Table 2. The overall quality of robustness, resourcefulness, redundancy, and rapidity was contributed by $11,7,4$, and 3 indicators, respectively. Figure 5 suggests a way to summarize and communicate the resilience quality scores using a five-level color scale to show the aggregated values. We can see that the current physical and environmental resilience quality scores are relatively low, especially the robustness and redundancy; and the robustness and resourcefulness of social-economic resilience are relatively low as well. However, the resourcefulness of physical resilience and the rapidity of institutional reliance have high scores which indicate the strengths of these aspects in coping with coastal hazards. According to the hazard mitigation plan and the city's master plan, if actions would be taken appropriately, the scores may be improved at all levels, as shown in Figure 4 .

\begin{tabular}{|l|l|l|l|l|}
\hline \multicolumn{1}{|c|}{2017} & Robustness & Redundancy & Resourceful & Rapidity \\
\hline Physical and environmental & & & & \\
\hline Social and economic & & & & \\
\hline Institutional & & & & \\
\hline
\end{tabular}

\begin{tabular}{|l|l|l|l|l|}
\hline \multicolumn{1}{|c|}{ Planned } & Robustness & Redundancy & Resourceful & Rapidity \\
\hline Physical and environmental & & & & \\
\hline Social and economic & & & & \\
\hline Institutional & & & & \\
\hline
\end{tabular}

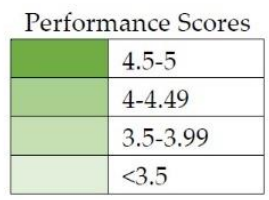

Figure 5. Aggregated scores for New Haven flood resilience qualities

\section{Discussion}

The quantitative coastal resilience assessment measures are flexible to be scaled up to regional resilience evaluation or scaled down to a community or specific disaster resilience assessment other than extreme storm events and flood hazards. Some indicators mentioned above can be broken down into subdivided indicators to reflect detailed factors 
and their performance. For example, the indicator of ecosystem and natural resources can be decomposed into the detailed indicators of riparian buffer protection, greenway corridor, inland wetlands and tidal marshes, and urban green space, etc.; social vulnerability index can be broken into health insurance, population below poverty, unemployed population, household without vehicle, etc.; regulation and policy can be divided into floodplain regulation and building codes, local flood hazard management policies, land acquisition and buyout policy, land use and zoning, planning tools, etc.

However, involving too many detailed indicators has the flaw of creating redundancy; although redundancy can be offset by weighting, this may complicate the process of scoring. It is crucial to balance detail and generalization of the indicator system. The 25 elements proposed in this study were independent of each other and generalized to cover the major aspects of coastal resilience.

\section{Conclusion}

The social-ecological system is a highly complicated human-nature interactive system that is similar to the ecological system. According to the capacities of ecological resilience: to absorb disturbances, self-organization, and learning and adaptation, the socialecological resilience has the similar abilities to undergo the system change and sustain itself, self-organize, and build the capacity to learn and adapt. But the human system has a preeminent capability to be proactive to changes or disturbance through monitoring, warning, preparedness, and the comprehensive decision-making system. The proactive planning process is different from learning and adapting after the events, but to prepare and comprehensively respond to the possible events or impacts with embracing uncertainty, which is the process of enhancing the resilience to the uncertainty.

The assessment framework proposed by this study combined hazard mitigation measures, climate adaptation strategies, and sustainable development goals to provide a practical methodology for resilience measurement and monitoring. The framework covers the dimensions of physical, environmental, social, economic, and institutional aspects and the critical factors that effect on resilience. It provides a system perspective to see how well the city copes with potential problems and what aspects can be improved to enhance the ability to respond to coastal hazards and disasters.

In the New Haven case, the problems of the densely populated low-lying urban area, artificially filled coastal industrial districts, lack of green space and natural shoreline buffer, and high social vulnerability make the city extremely vulnerable to coastal storm and flooding hazards. The resilience assessment examined the capacity of the city to cope with these problems and found that it has the strengths of sound basic livelihood protection, well-maintained infrastructure, well-prepared emergency facilities, as well as the floodplain management regulations and adaptation planning, etc.; while the city also faces the weakness of social-economic disadvantages, limited climate adaptation investment, and other issues. The assessment framework provides a comprehensive understanding of the current situation and supports prioritizing the actions and projects that are most needed; it is performing as a practical monitoring tool and decision-making support system. 
Funding: This research received no external funding.

Acknowledgments: The authors acknowledge the support of Connecticut Institute for Resilience \& Climate Adaptation (CIRCA) of USA, for providing the project of New Haven and Fairfield county resilience planning, as well as the Climate Corps of the University of Connecticut for providing valuable expertise and teaching assistant funding.

Conflicts of Interest: The authors declare no conflict of interest,

\section{References}

1. Ramesh R.; Chen Z.; Cummins V., et al. Land-Ocean interactions in the coastal zone: Past, present \& future. Anthropocene 2015, 12:85-98. doi: 10.1016/j.ancene.2016.01.005.

2. Melillo, J. M.; Richmond T.C.; Yohe G., Eds. Climate Change Impacts in the United States: The Third National Climate Assessment 2014. U.S. Global Change Research Program, 841 pp. doi:10.7930/J0Z31WJ2.

3. Azzam A.; Belhaj Ali A. Urban Sprawl in Wadi Goss Watershed (Jeddah City/Western Saudi Arabia) and Its Impact on Vulnerability and Flood Hazards. Journal of Geographic Information System 2019, 11. 371-388. doi: 10.4236/jgis.2019.113023.

4. Mustafa A.; Bruwier M.; Archambeau P., et al. Effects of spatial planning on future flood risks in urban environments. Journal of Environmental Management 2018, 225:193-204. doi: 10.1016/j.jenvman.2018.07.090.

5. Holling C.S. Simplifying the complex: The paradigms of ecological function and structure. European Journal of Operational Research 1987, 30(2): 139-146.

6. Holling C.S. Understanding the complexity of economic, ecological, and social systems. Ecosystems 2001, 4(5):390-405. doi: 10.1007/s10021-001-0101-5.

7. Newman P. Resilient cities: Responding to peak oil and climate change. Island Press: Washington, DC, USA, 2009.

8. Klein R.J.T.; Smit M.J.; Goosen H.;, Hulsbergen C.H. Resilience and vulnerability: Coastal Dynamics or Dutch Dikes? The Geographical Journal 1998, 164(3):259-268. doi: 10.2307/3060615.

9. Lafortezza R.; Chen J.; Van den Bosch, C.K., Randrup T.B. Nature-based solutions for resilient landscapes and cities. Environmental Research 2018, 165:431-441. doi: 10.1016/j.envres.2017.11.038.

10. Powell E.J.; Tyrrell M.C.; Milliken A.; Tirpak J.M.; Staudinger M.D. A review of coastal management approaches to support the integration of ecological and human community planning for climate change. Journal of Coastal Conservation 2018, 23(1):1-18. doi: 10.1007/s11852-018-0632-y.

11. Beatley T. Planning for coastal resilience: Best practices for calamitous times. Island Press: Washington, DC, USA, 2009.

12. Manyena S.B. The concept of resilience revisited. Disasters 2006, 30(4):434-450. doi: 10.1111/j.0361-3666.2006.00331.x.

13. Vale L.J.; Campanella T.J. The resilient city: How modern cities recover from disaster. Oxford University Press: Oxford, UK, 2005.

14. Berke P.R.; Campanella T.J. Planning for Postdisaster Resiliency. The ANNALS of the American Academy of Political and Social Science 2006, 604(1):192-207. doi:10.1177/0002716205285533

15. McCarthy J.J.; Canziani O.F.; Leary N.A.; Dokken D.J.; White K.S., Eds. Climate Change 2001: Impacts, Adaptation, and Vulnerability: Contribution of Working Group II to the Third Assessment Report of the Intergovernmental Panel on Climate Change. Cambridge University Press: Cambridge, UK, 2001. Available online: https://www.ipcc.ch/report/ar3/wg2/

16. Godschalk D.R. Urban hazard mitigation: Creating resilient cities. Natural Hazards Review 2003, 4(3):136-143. doi: 10.1061/(ASCE)1527-6988(2003)4:3(136).

17. Füssel H. Vulnerability: A generally applicable conceptual framework for climate change research. Global Environmental Change 2007, 17(2):155-167. doi: 10.1016/j.gloenvcha.2006.05.002.

18. Eriksen S.H.; Kelly P.M. Developing credible vulnerability indicators for climate adaptation policy assessment. Mitigation and Adaptation Strategies for Global Change 2007, 12(4):495-524. doi: 10.1007/s11027-006-3460-6.

19. Klein, R.J.T. Adaptation to climate variability and change: What is optimal and appropriate. In Climate Change in the Mediterranean: Socio-Economic Perspectives of Impacts, Vulnerability and Adaptation pp. 32-50. Edward Elgar Publishing: Cheltenham, UK, 2003. Available online: https://www.researchgate.net/publication/279571584_Adaptation_to_climate_variability_and_change_what_is_optimal_and_appropriate

20. Adger W.N.; Hughes T.P.; Folke C.; Carpenter S.R.; Rockström J. Social-ecological resilience to coastal disasters. Science 2005, 309(5737):1036-1039. doi: 10.1126/science.1112122.

21. Balica S.F.; Wright N.G.; Van der Meulen F. A flood vulnerability index for coastal cities and its use in assessing climate change impacts. Natural Hazards 2012, 64(1):73-105. doi: 10.1007/s11069-012-0234-1.

22. DasGupta R.; Shaw R. An indicator based approach to assess coastal communities' resilience against climate related disasters in Indian Sundarbans. Journal of Coastal Conservation 2015, 19(1):85-101. doi: 10.1007/s11852-014-0369-1.

23. Karamouz M.; Zahmatkesh Z. Quantifying resilience and uncertainty in coastal flooding events: Framework for assessing urban vulnerability. Journal of Water Resources Planning and Management 2017, 143(1):04016071. doi: 10.1061/(ASCE)WR.19435452.0000724 .

24. U.S. Indian Ocean Tsunami Warning System Program (USIOTWSP). How Resilient is Your Coastal Community? A Guide for evaluating coastal community resilience to tsunamis and other coastal hazards 2007. Available online: https://www.crc.uri.edu/download/CCRGuide_lowres.pdf

25. Cutter S.L.; Barnes L.; Berry M.. et al. A place-based model for understanding community resilience to natural disasters. Global Environmental Change 2008, 18(4):598-606. doi: 10.1016/j.gloenvcha.2008.07.013. 
26. Cutter S.L.; Boruff B.J.; Shirley W.L. Social vulnerability to environmental hazards. Social Science Quarterly 2003, 84(2):242-261. doi: 10.1111/1540-6237.8402002.

27. Peacock W.G. Advancing the Resilience of Coastal Localities: Developing, Implementing and Sustaining the Use of Coastal Resilience Indicators: A Final Report 2010. Available online: https://www.researchgate.net/publication/254862206_Final_Report_Advancing_the_Resilience_of_Coastal_Localities_10-02R

28. Teo M.; Goonetilleke A.; Ziyath A.M. An integrated framework for assessing community resilience in disaster management. In Proceedings of the 9th Annual International Conference of the International Institute for Infrastructure Renewal and Reconstruction, Riskinformed Disaster Management: Planning for Response, Recovery and Resilience 2013. Available online: https://www.researchgate.net/publication/258225443_An_integrated_framework_for_assessing_community_resilience_in_disaster_management

29. Windle G.; Bennett K.M.; Noyes J. A methodological review of resilience measurement scales. Health and Quality of Life Outcomes 2011, 9(1):8. doi: 10.1186/1477-7525-9-8.

30. Charlier R.H. Encyclopedia of coastal science. Journal of Coastal Research. 2005, 21(4):866. doi: 10.2112/15515036(2005)21[866:BR]2.0.CO; 2.

31. Sohn W.; Brody S.D.; Kim J.; Li M. How effective are drainage systems in mitigating flood losses? Cities 2020, 107:102917. doi: 10.1016/j.cities.2020.102917.

32. Demuzere M.; Orru K.; Heidrich O.; Olazabal E.; Geneletti D.; Orru H.; Bhave A.G.; Mittal N.; Feliu E.; Faehnle M. Mitigating and adapting to climate change: Multi-functional and multi-scale assessment of green urban infrastructure. Journal of environmental management 2014, 146C. 107-115. 10.1016/j.jenvman.2014.07.025.

33. Aldunce P.; Beilin R.; Handmer J.; Howden M. Stakeholder participation in building resilience to disasters in a changing climate. Environmental hazards 2016,15(1):58-73. doi: 10.1080/17477891.2015.1134427.

34. Booth L.; Schueller L.A.; Scolobig A.; Marx S. Stakeholder solutions for building interdisciplinary and international synergies between climate change adaptation and disaster risk reduction. International journal of disaster risk reduction 2020, 46:101616. doi: 10.1016/j.ijdrr.2020.101616.

35. Peterson J. A New Coast: Strategies for Responding to Devastating Storms and Rising Seas. Island Press: Washington, DC, USA, 2009. 